\title{
Vaccine Candidates against Nontypeable Haemophilus influenzae: a Review
}

\author{
Ava Behrouzi ${ }^{1}$, Farzam Vaziri ${ }^{1,2}$, Fatemeh Rahimi-Jamnani ${ }^{1,2}$, Parviz Afrough ${ }^{1,2}$, \\ Mohammad Rahbar ${ }^{3}$, Fereshteh Satarian ${ }^{1}$ and Seyed Davar Siadat ${ }^{* 1,2}$ \\ ${ }^{1}$ Department of Mycobacteriology and Pulmonary Research, Pasteur Institute of Iran, Tehran, Iran; ${ }^{2}$ Microbiology \\ Research Center, Pasteur Institute of Iran, Tehran, Iran; ${ }^{3}$ Department of Microbiology, Reference Health \\ Laboratories Research Center, Ministry of Health and Medical Education, Tehran, Iran
}

Received 1 October 2016; revised 17 October 2016; accepted 30 October 2016

\begin{abstract}
Nonencapsulated, nontypeable Hemophilus influenzae (NTHi) remains an important cause of acute otitis and respiratory diseases in children and adults. NTHi bacteria are one of the major causes of respiratory tract infections, including acute otitis media, cystic fibrosis, and community-acquired pneumonia among children, especially in developing countries. The bacteria can also cause chronic diseases such as chronic bronchitis and chronic obstructive pulmonary disease in the lower respiratory tract of adults. Such bacteria express several outer membrane proteins, some of which have been studied as candidates for vaccine development. Due to the lack of effective vaccines as well as the spread and prevalence of NTHi worldwide, there is an urgent need to design and develop effective vaccine candidates against these strains. DOI: 10.18869/acadpub.ibj.21.2.69
\end{abstract}

Keywords: Vaccines, Chronic obstructive pulmonary disease, Haemophilus influenzae

Corresponding Author: Seyed Davar Siadat

Department of Mycobacteriology and Pulmonary Research, Pasteur Institute of Iran, Tehran, Iran; Tel.: (+98-21) 64112823;

E-mail: d.siadat@gmail.com

\section{INTRODUCTION}

$H$ aemophilus influenzae was first isolated from sputum samples of patients suffering from influenza during influenza pandemics in 1892. However, the bacterium was mistakenly considered as causative agent of influenza disease until 1933, when the viral etiology of influenza became known ${ }^{[1]}$. In 1931, encapsulated and nonencapsulated $H$. influenzae strains were introduced and six various serotypes (a, b, c, d, e, and f) were found for encapsulated $H$. influenzae. Among them, H. influenzae type b (Hib) is known to be a major virulent pathogen ${ }^{[2-4]}$. Hib conjugate vaccines are able to eradicate the invasive Hib disease in children throughout the world. Additionally, such conjugate vaccines can induce protective humoral immune responses and decline circulating Hib strains among population through decreased nasopharyngeal carriage of Hib. Taken together, it can be deduced that such conjugate vaccines significantly affect the incidence of $H$. influenzae disease and the subsequent colonization in the respiratory tract ${ }^{[5-9]}$.

\section{Microbiology}

$H$. influenzae is a small, nonmotile, Gram-negative coccobacillus that requires special growth factors, such as $\mathrm{X}$ (hemin) and $\mathrm{V}$ (nicotinamide adenine dinucleotide). The bacterium is generally an anaerobe but can grow as facultative anaerobic organisms. $H$. influenzae can be found, as a part of the normal microflora, in the upper respiratory tractespecially oropharynx and nasopharynx, of about $90 \%$ of adults. Therefore, $H$. influenzae may act as opportunistic pathogens, particularly in patients suffering from viral infections or compromised immune systems ${ }^{[10]}$.

\section{Diseases caused by haemophilus}

$\mathrm{Hib}$ is responsible for several infections such as bactremia, epiglottitis, otitis media, acute pharyngitis 
bronchitis pneumonia, acute bacterial meningitis, endocarditis, and conjunctivitis in infants and small children. The emergence of Hib protein-polysaccharide conjugate vaccines, in the late 1980 s, led to the control and elimination of Hib-related diseases and Hib carriage rates in several industrialized countries ${ }^{[11]}$. Encapsulated $H$. influenzae strains, except for serotype b, have long been known to be nonvirulent strains associated with rare diseases. Nevertheless, the replacement of $\mathrm{Hib}$ with other capsule types has been proposed as a candidate for vaccines against invasive diseases caused by $H$. influenzae serotypes a, e, and f. Nonencapsulated, nontypeable $H$. influenzae (NTHi) bacteria are one of the major causes of respiratory tract infections, including acute otitis media (AOM), cystic fibrosis, and community-acquired pneumonia among children, especially in developing countries The bacteria are also known to cause chronic bronchitis and chronic obstructive pulmonary disease (COPD) in the adult lower respiratory tract ${ }^{[12]}$.

Nontypeable $H$. influenzae, as the main etiology of otitis media, can be established and developed in the lower respiratory tract of adults with COPD. It is important to note that COPD is the fourth leading cause of mortality around the world, which results in disease exacerbation ${ }^{[13,14]}$.

NTHi bacteria have been indicated to play a role in the formation of biofilms in the respiratory tract of adults with COPD, similar to that observed with Pseudomonas aeruginosa in patients with cystic fibrosis ${ }^{[15]}$. Biofilms are a unique community of bacterial cells surrounded by their own polymer matrix that attaches to solid surfaces. Approximately $99.9 \%$ of the bacteria naturally exhibit a biofilm on different surfaces, which, unlike planktonic bacteria, have the ability to develop resistance to antibiotics and immune clearance mechanisms. Therefore, it is necessary to clarify the importance of biofilm formation in bacterial pathogens for the development of appropriate approaches to control infections caused by bacteria in biofilms such as otitis media with effusion. NTHis, Streptococcus pneumoniae and Moxarella catarrhalis, are believed to be major causes of adult pneumonia. However, the virulence of NTHi is typically less than that of $S$. pneumonia; NTHi bacteria are often associated with underlying lung diseases ${ }^{[14,16,17]}$.

\section{Virulence factors of NTHi \\ Fimbrial adhesion}

Fimbriae, as a colonization factor, are appendages of $H$. influenzae that facilitate bacterial adherence to human cells. Fimbriae play an important role in the first step of infections through bacterial adherence to human mucosal epithelial cells.

\section{Lipooligosaccharide (LOS)}

LOSs are cell wall-associated glycolipids composed of a lipid A linked to a series of oligosaccharide components (with various molecular sizes) through 2keto-3-deoxyoctulosonic acid. The LOS is considered as a surface adhesion that helps $H$. influenzae colonization in the airway ${ }^{[18]}$.

\section{IgA proteases}

IgA proteases are endopeptidases (types 1 and 2) secreted by NTHi to cleave and neutralize immuneglobulin A1. Studies have demonstrated that almost all of the NTHi strains can synthesize at least one of these IgA proteases ${ }^{[19]}$. These enzymes are able to inactivate human $\operatorname{IgA} 1$ present in the nasopharynx, leading to the inactivation of more than $90 \%$ of $\operatorname{IgA} 1 \mathrm{~s}^{[20]}$. More importantly, recent studies have demonstrated that almost all NTHi strains are able to secrete the IgA protease $^{[21]}$.

\section{Opacity-associated protein A (OapA)}

All $H$. influenzae strains have an OapA with a low molecular weight $(47 \mathrm{kDa})$. OapA plays important roles in pharyngeal colonization and bacterial adherence to epithelial cells in cell culture ${ }^{[22]}$.

\section{Epidemiology}

Nontypeable $H$. influenzae strains are considered to be one of the most common commensal organisms in the human nasopharynx. Approximately $20 \%$ of infants within the first year of their life are colonized with nontypeable $H$. influenzae strains, followed by highlevel colonization during adulthood. Unlike adults who typically carry only one type, children are often colonized with multiple strains simultaneously ${ }^{[23]}$.

Based on statistics, NTHi strains are responsible for $20-30 \%$ of all episodes of AOM and possibly a higher percentage of recurrent episodes. In addition, NTHi strains account for more than $40 \%$ of otitis media with effusion cases (chronic otitis media), and about onethird of acute or chronic sinusitis is also caused by NTHi strains. NTHi can be considered as the cause of chronic bronchitis, pulmonary exacerbations, and community-acquired pneumonia, especially among children living in developing countries, patients with underlying chronic lung disease, as well as the elderly individuals. In some cases, $H$. influenzae has been introduced as the agent responsible for systemic diseases such as meningitis, septicemia, and septic $\operatorname{arthritis}^{[24,25]}$

Nasopharyngeal NTHi colonization leads to the risk of respiratory tract diseases ${ }^{[26]}$. Smoking results in goblet cell hyperplasia, mucus hypersecretion, and decreased respiratory epithelial cell ciliary function, 
presumably elevating the localization of NTHimediated respiratory tract diseases. Underlying anatomic abnormalities or compromised immunities make patients prone to systemic diseases caused by $\mathrm{NTHi}^{[27]}$. Although NTHi-related diseases can be successfully treated with the commonly used $\beta$-lactam antibiotics such as ampicillin or amoxicillin, resistance among the bacteria is rising increasingly through different mechanisms such as $\beta$-lactamase ${ }^{[26]}$ or through modified penicillin-binding proteins with low affinity for $\beta$-lactams. In addition, various studies have reported the emergence of resistance to trimethoprimsulfamethoxazole, clarithromycin, and azithromycin. One of the important dimensions of this phenomenon is economic issues, including the cost of physician visits and medications, which is estimated around $\$ 1$ billion per year in the United States ${ }^{[28,29]}$.

\section{Vaccines}

There are a variety of effective vaccines widely used against Hib strains; however, none of which provide enough protection to children. It is well-documented ${ }^{[30,}$

${ }^{31]}$ that protein carriers of polyribosylribitol phosphate (PRP)-conjugated vaccines have the potential ability to induce antibody responses in infants at the peak age incidence of Hib infection.

Antibodies generated against PRP, the polysaccharide capsule of $H i b$, provide protection against the Hib disease. However, the purified PRP used in the first generation of Hib vaccines failed to induce adequate immune responses in children younger than 18 months, who are too susceptible to the Hib disease. Carrier protein PRP-conjugates leads to improved immunogenicity of the vaccine and generation of a protective response to Hib diseases in young infants. In spite of their sustained immunegenicity and high efficacy, Hib conjugate vaccines failed to provide protection against Hib infections in a small number of infants. The children vaccinated with Hib seem to have a defect in immunological priming with lower-affinity antibodies to Hib capsular polysaccharide. some investigations ${ }^{[32,33]}$ have been conducted to find novel vaccines based on some of the surface-exposed $H$. influenzae proteins such as pili and outer membrane proteins (OMPs). Such vaccines reflect high protective efficacies against Hib and NTHi infections. Nonetheless, there is a need for further studies to characterize bacterial structures for discovery of protective vaccine antigens. This goal may not be easily achieved in practice for such bacteria due to their extensive sequence and antigenic variations among gene products interacting with the immune system such as OMPs, adhesins, lipopolysaccharides (LPSs) and secreted virulence factors ${ }^{[32-39]}$.

\section{Vaccination strategies for NTHi infections}

Despite the widespread availability of antibiotics, NTHi infections are considered as major causes of morbidity and mortality, which emphasizes the importance of development of protective vaccine candidates against NTHi infections. However, it is difficult to develop an appropriate vaccine because NTHi strains, as commensal bacteria, are predominantly present on mucosal surfaces, particularly in the airways as parts of natural flora. These organisms are genetically very diverse; therefore, there are no genetic markers to differentiate NTHi strains by the existing typing systems.

There are antibodies against OMPs and LPSs in human serum. Therefore, most of the studies on human immunity against NTHi infections have focused on identification of those OMPs with immunogenic and antigenic properties that are essential for colonization, invasion, and survival within the human host ${ }^{[40]}$. These low-molecular-weight proteins of $H$. influenzae are classified into major OMPs, including P1, P2, and P4$\mathrm{P} 6$, and minor OMPs, including the transferrin binding protein 1,2 (Tbp1/Tbp2) and protein $\mathrm{D}$. The use of OMP P2, as a vaccine candidate, has been limited due to its highly heterogeneity and subsequent antigenic drift during persistent infections in patients with chronic bronchitis ${ }^{[41,42]}$.

\section{Outer membrane proteins: vaccine candidates}

\section{P1}

P1 is a heat-modifiable protein with a molecular mass of $35 \mathrm{kDa}$ at room temperature and $46-50 \mathrm{kDa}$ after boiling. Even though exhibiting high antigenic variations in its surface-exposed epitopes, P1 is highly immunogenic, which can induce protective antibodies against NTHi-induced otitis media in chinchillas. Relatively protective efficiency of antibodies generated by $\mathrm{P} 1$ has been studied in the infant rat bacteremic $\operatorname{model}^{[43]}$.

\section{$P 2$}

$\mathrm{P} 2$ is the most abundant OMP with a molecular mass ranging from 36 to $42 \mathrm{kDa}$. The protein can be found in all strains as a trimeric porin structure, allowing molecules up to $1400 \mathrm{Da}$ to diffuse across the membrane. Different NTHi strains are highly variable in P2 amino acid sequences. There are 16 relatively conserved transmembrane regions and 8 heterogeneous surface-exposed loops in $\mathrm{P} 2^{[44,45]}$.

\section{P4}

OMP P4 is a highly-conserved cationic lipoprotein with molecular mass of 28 to $30 \mathrm{kDa}$, designated as lipoprotein $e$, in all strains of $H$. influenzae $e^{[20]}$. The 
presence of hemin-binding motifs within $\mathrm{P} 4$ and the construction of $H$. influenzae hel mutants incapable of aerobic growth indicate the vital role of $\mathrm{P} 4$ in heme acquisition $^{[20]}$. In spite of the fact that lipoprotein $e$ plays a role in transporting exogenous heme into the cell, the biochemistry of heme binding and transport remains to be elucidated ${ }^{[46,47]}$.

\section{P6}

P6, with a molecular mass of $16 \mathrm{kDa}$, is one of the significant outer membrane lipoproteins that plays a strong immunoregulatory role similar to other lipoproteins containing an N-terminal tri-palmitoyl cysteine (Cys-Pam3) motif. P6 significantly induces the secretion of IL- 8 and TNF-a in macrophages. The protein, as a common determinant among all typeable and nontypeable $H$. influenzae strains, has one epitope that is highly conserved among nontypeable strains. P6 has been suggested as an important antigen in human immunity to $H$. influenzae. Antibodies produced against P6 protein with peptidoglycan from a type $b$ strain indicated a protective role for infant rats in a model of $H$. influenzae infection. A monoclonal antibody of (7F3) raised against P6 has the ability to disrupt bactericidal activity of human serum against NTHi. Bactericidal activity of serum for NTHi was reduced by depleting normal human serum of antibody to P6 by the affinity chromatography ${ }^{[48-51]}$.

\section{Tbp1 and Tbp2}

In vitro experiments have shown that $H$. influenzae is able to absorb iron from human transferrin through two transferring-binding proteins, Tbp1 and Tbp2, expressed on bacterial cell surfaces. These proteins are produced during infection probably to acquire iron in vivo. The lack of these proteins severely impairs the bacterial growth. Various studies have demonstrated ${ }^{[52]}$ the presence of antibodies against both Tbp1 and Tbp2 in convalescent-phase sera. Genes-encoding Tbp1 (tbpA) and Tbp2 (tbpB) in H. influenzae have recently been cloned and sequenced. Accordingly, Tbp1 has been demonstrated to play a vital role in the growth of isogenic mutants in human transferrin, while a mutant with no Tbp2 showed severely limited growth on transferrin-bound iron ${ }^{[53,54]}$.

\section{D protein}

Protein D (PD) is originally a surface-exposed OMP of $H$. influenzae with the ability to bind to the human IgD myeloma protein $4490^{[55]}$. Cloning and characterization of the $h p d$ gene from $H$. influenzae indicated that PD, as an hpd gene product, binds to the 125I-labeled IgD myeloma protein. The interaction between $H$. influenzae and the immune system is occurred by the binding of $\operatorname{IgD}$ to its surface ${ }^{[56]}$; this interaction is shared with Moraxella (Branhamella) catarhalis with unknown reasons. All $127 \mathrm{H}$. influenzae strains, including encapsulated serotypes a-f and NTHi, have this antigenically conserved $42-\mathrm{kDa}$ protein $^{[57]}$, making it an attractive vaccine candidate. A 1092 bp open reading frame of $h p d$ encodes a 364amino acid protein. The nucleotide and deduced amino acid levels have $97 \%$ identical sequences, and the substitutions are relatively evenly distributed across the gene. PD is a natural lipoprotein whose signal sequence contains a consensus sequence for bacterial lipoproteins, Leu-Ala-Gly-Cys, as amino acids 16 to $19^{[58]}$. There are a minimum of 12 lipoproteins in $H$. influenzae ${ }^{[59]}$, one of which is PD. When the lipoprotein is secreted, the amino-terminal cysteine residue is modified after translation through added glycerol moiety containing ester-linked fatty acids. In the next step, the signal peptide is cleaved by signal peptidase II specific for lipoproteins, and the newlyformed amino terminus is further acylated with an amide-linked fatty acid. Therefore, membrane anchor is developed by the fatty acids linked to the aminoterminal cysteine residue ${ }^{[60]}$.

No specific functions were assigned to PD; however, in vivo and in vitro studies have shown that $\mathrm{PD}$ has a role in NTHi pathogenesis due to the absence of antigenic drift and surface localization. Despite the fact that it is not an adhesion PD can indirectly stimulate attachment and invasion via the glycerophosphodiester phosphodiesterase activity required for transferring choline from the host to $\operatorname{LOS}$ of $H$. influenzae ${ }^{[60,61]}$. Bacterial invasion is enhanced by signaling ChoP+LOS variants through the platelet- activating factor receptor ${ }^{[62,63]}$. Glycero-phosphorylcholine is one of the greatest degradation products of eukaryotic membrane-associated phosphor-lipids that can be hydrolyzed by PD because of its GlpQ activity. Glycerophosphorylcholine has the ability to produce glycerol 3-phosphate and choline in order to achieve choline directly from host epithelial cells ${ }^{[64]}$. The phosphorylcholine-decorated LOS serves as a ligand for the platelet-activating factor receptor of bronchial epithelial cells. In a chinchilla model of AOM, the presence of phosphorylcholine leads to the increased formation of stable biofilm communities of $\mathrm{NTHi}^{[65]}$.

PD has shown $67 \%$ structural identity with $g l p Q$ encoded by the periplasmic glycerophosphodiester phosphodiesterase enzyme in Escherichia coli. This periplasmic glycerophosphodiesterase, encoded by $g l p Q^{[66,67]}$, is a membrane-bound protein in $H$. influenzae through fatty acids linked to a cysteine residue in a consensus sequence for bacterial lipoproteins $^{[68,69]}$. PD, mutated with no cysteine residue, is hydrophilic and could not be acylated. The 
nonacylated PD can be secreted into the periplasmic space of $E$. coli, indicating the role of acylation in hydrophobicity of PD as an outer membrane-anchored lipoprotein $^{[68]}$. PD also increases bacterial adhesion and internalization into human monocytes. In vivo and in vitro studies have demonstrated that the NTHi virulence in the upper respiratory tract is related to PD expression. For instance, a 100 fold decrease in virulence was found in a PD-deficient strain compared to the PD-expressing strain in a rat model of otitis media. In addition, culture specimens, inoculated with the PD-deficient NTHi compared with isogenic wild type NTHi, indicated a reduction in the onset of ciliary activity after 12 hours. Ciliary dysfunction was significantly higher in the PD-expressing strain, as compared to the PD-negative mutant $(P<0.01)$. In addition, a significant loss of cilia was observed in the PD-expressing strain after 48-hour incubation, indicating that $\mathrm{PD}$ is responsible for etiology of upper respiratory tract infection caused by NTHi, probably due to increased functional and morphological damages to ciliated epithelial cells. Based on a study on animal models, the protective antibodies against NTHi otitis media in rat and chinchilla were provoked by $\mathrm{PD}^{[42,69-72]}$.

\section{D15 protein}

OMP D15, a protein with a molecular weight of approximately $80 \mathrm{kDa}$, is available in both encapsulated and nonencapsulated Hemophilus strains $^{[73]}$.

\section{HMW1 and HMW2 (high molecular weight 1 and 2) proteins}

HMW proteins, such as HMW1 and HMW2, are found in about $70 \%$ of Hemophilus strains. These proteins have heterogeneity area in different nontypeable Haemophilus strain. The remaining $25 \%$ of Hemophilus strains lack the protein, which is an immunogenic protein expressed in Hemophilus influenzae type a (Hia) ${ }^{[63]}$.

\section{Hia protein}

Hia is one of the most important binding proteins that is expressed in some strains of Hib and provides an efficient attachment to the epithelial cells. Hia is a surface-exposed protein whose amino acids 221-779 are involved in the binding. The protein is a member of the autotransporter family, and almost all of the strains have this protein, except for the strains having lost HMW proteins ${ }^{[7]}$.

\section{Hap (heterogeneous nuclear ribonucleoprotein A1- interacting protein)}

Hap is a binding protein found in all or most strains of Hemophilus, showing a high level of protection in many animal model studies. The protein is a member of the autotransporter family that allows bacteria to attach to epithelial cells and extracellular matrix proteins, facilitating the possibility of bacterial aggregation and biofilm formation ${ }^{[75,76]}$.

\section{Conclusion}

NTHi is one of the most important causes of acute middle ear infections in children and respiratory diseases in adults. Since the introduction of conjugate vaccines against the bacteria encapsulated Hib in the late $1980 \mathrm{~s}$, the prevalence of invasive diseases caused by Hib has decreased significantly in developed countries; however, invasive diseases caused by NTHi strains have spread and, in many areas, lead to invasive diseases. The lack of a protection capsule, high antigenic heterogeneity, and high changes in exposed antigens are significant barriers to the development of effective vaccines against NTHi. Therefore, studies investigating vaccine development have focused on the protectively area of the external membrane proteins, LOS, and pili. To this end, various vaccine candidates have been developed with the immunogenicity of PD, providing high protection against NTHi.

CONFLICT OF INTEREST. None declared.

\section{REFERENCES}

1. Kuhnert P, Christensen H. Pasteurellaceae: Biology, Genomics and Molecular Aspects. Caister Academic Press: Uk; 2008.

2. Pittman M. Variation and type specificity in the bacterial species Hemophilus influenzae. The journal of experimental medicine 1931; 53(4): 471- 492.

3. Elliott JA, Pigott N, Cochi SL, Facklam RR. Major subtypes of invasive Haemophilus influenzae from 1983 to 1985 in Atlanta. Ga. Journal of clinical microbiology 1990; 28(25): 833-836.

4. Jin Z, Romero-Steiner S, Carlone GM, Robbins JB, Schneerson R. Haemophilus influenzae type a infection and its prevention. Infection and immunity 2007; 75(6): 2650- 2654.

5. Singleton R, Hammitt L, Hennessy T, Bulkow L, DeByle C, Parkinson A, Cottle TE, Peters H, Butler JC. The Alaska Haemophilus influenzae type b experience: lessons in controlling a vaccine-preventable disease. Pediatrics 2006; 118(2): e421- 429.

6. Boisvert AA, Moore D. Invasive disease due to Haemophilus influenzae type A in children in Canada's north: A priority for prevention. Canadian journal of infectious diseases and medical microbiology 2015; 
26(6): 291- 292.

7. Collins S, Vickers A, Ladhani SN, Flynn S, Platt S, Ramsay ME, Litt DJ, Slack MP. Clinical and Molecular Epidemiology of Childhood Invasive nontypeable Haemophilus influenzae disease in england and wales. The pediatric infectious disease journal 2016; 35(3): e76- e84.

8. Pickering JW, Martins TB, Schroder MC, Hill HR. Comparison of a multiplex flow cytometric assay with enzyme-linked immunosorbent assay for auantitation of antibodies to tetanus, diphtheria, and Haemophilus influenzae Type b. Clinical and diagnostic laboratory immunology 2002; 9(4): 872-876.

9. Langereis J, de Jonge MI. Invasive disease caused by nontypeable haemophilus influenzae. Emerging infectious diseas 2015; 21(10):1711-1718.

10. Herbert M, Crook D, Moxon ER. Molecular Methods for Haemophilus influenzae. Methods in molecular medicine 1998; 15: 243-263.

11. Saez-Llorens X, McCracken GH. Bacterial meningitis in children. The lancet 2003; 361(9375): 2139-2148.

12. Adderson E, Byington CL, Spencer L, Kimball A, Hindiyeh M, Carroll K, Mottice S, Korgenski EK, Christenson JC, Pavia AT. Invasive serotype a Haemophilus influenzae infections with a virulence genotype resembling Haemophilus influenzae type $b$ : emerging pathogen in the vaccine era? Pediatrics 2001; 108(1): e18.

13. Urwin G, Krohn JA, Deaver-Robinson K, Wenger JD, Farley MM. Invasive disease due to Haemophilus influenzae serotype f: clinical and epidemiologic characteristics in the $\mathrm{H}$. influenzae serotype $\mathrm{b}$ vaccine era. The Haemophilus influenzae study group. Clinical infectious diseases 1996; 22(6): 1069-1076.

14. Bruun B, Gahrn-Hansen B, Westh H, Kilian M. Clonal relationship of recent invasive Haemophilus influenzae serotype $\mathrm{f}$ isolates from Denmark and the United States. Journal of medical microbiology 2004; 53(Pt 11): 11611165.

15. Wu S, Li X, Gunawardana M, Maguire K, GuerreroGiven D, Schaudinn C, Wang C, Baum MM, Webster P. Beta- lactam antibiotics stimulate biofilm formation in non-typeable Haemophilus influenzae by up-regulating carbohydrate metabolism. PLoS One 2014; 9(7): e99204.

16. Murphy TF. The role of bacteria in airway inflammation in exacerbations of chronic obstructive pulmonary disease. Current opinion in infectious diseases 2006; 19(3): 225-230.

17. Murphy TF. Respiratory infections caused by nontypeable Haemophilus influenzae. Current opinion in infectious diseases 2003; 16(2): 129-134.

18. Rahman M, Gu XX, Tsai CM, Kolli VS, Carlson RW. The structural heterogeneity of the lipooligosaccharide (LOS) expressed by pathogenic non-typeable Haemophilus influenzae strain NTHi 9274. Glycobiology 1999; 9(12):1371-1380.

19. Grundy FJ, Plaut AG, Wright A. Localization of the cleavage site specificity determinant of Haemophilus influenzae immunoglobulin A1 protease genes. Infection and immunity 1990; 58(2): 320-331.

20. Devenyi A, Plaut AG, Grundy FJ, Wright A. Postinfectious human serum antibodies inhibit IgA1 proteinases by interaction with the cleavage site specificity determinant. Molecular immunology 1993; 30(14): 1243-1248.

21. Bricker J, Mulks MH, Plaut AG, Moxon ER, Wright A. IgA1 proteases of Haemophilus influenzae: cloning and characterization in Escherichia coli K-12. Proceedings of the national academy of sciences of the united states 1983; 80(9): 2681-2685.

22. Prasadarao NV, Lysenko E, Wass CA, Kim KS, Weiser JN. Opacity-associated protein A contributes to the binding of Haemophilus influenzae to chang epithelial cells. Infection and immunity 1999; 67(8): 4153- 4160.

23. Giufre M, Daprai L, Cardines R, Bernaschi P, Ravà L, Accogli M, Raponi M, Garlaschi ML, Ciofi degli Atti ML, Cerquetti M. Carriage of Haemophilus influenzae in the oropharynx of young children and molecular epidemiology of the isolates after fifteen years of $H$. influenzae type b vaccination in Italy. Vaccine 2015; 33(46): 6227-6234.

24. Murphy TF, Sethi S, Klingman KL, Brueggemann AB, Doern GV. Simultaneous respiratory tract colonization by multiple strains of nontypeable Haemophilus influenzae in chronic obstructive pulmonary disease: implications for antibiotic therapy. The journal of infectious diseases 1999; 180(2): 404-409.

25. Sethi S, Evans N, Grant BJ, Murphy TF. New strains of bacteria and exacerbations of chronic obstructive pulmonary disease. The new england journal of medicine 2002; 347(7): 465-471.

26. Michaels RH, CS Poziviak, FE Stonebraker, CW Norden. Factors affecting pharyngeal Haemophilus influenzae type b colonization rates in children. Journal of clinical microbiology 1976; 4(5): 413-417.

27. Michaels RH, Stonebraker FE, Robbins JB. Use of antiserum agar for detection of Haemophilus influenzae type b in the pharynx. Pediatric research 1975; 9(5) :513-516.

28. Mpairwe Y. Observations on the nasopharyngeal carriage of Haemophilus influenzae type b in children in Kampala. Uganda. The journal of hygiene 1970; 68(2): 337-341.

29. Peerbooms PG, Engelen MN, Stokman DA, van Benthem BH, van Weert ML, Bruisten SM, van Belkum A, Coutinho RA. Nasopharyngeal carriage of potential bacterial pathogens related to day care attendance, with special reference to the molecular epidemiology of Haemophilus influenzae. Journal of clinical microbiology 2002; 40(8): 2832-2836.

30. Rana R, Dalal J, Singh D, Kumar N, Hanif S, Joshi N, Chhikara MK. Development and characterization of Haemophilus influenzae type $\mathrm{b}$ conjugate vaccine prepared using different polysaccharide chain lengths. Vaccine 2015; 33(23): 2646-2654.

31. Kelly DF, Moxon ER, Pollard AJ. Haemophilus influenzae type b conjugate vaccines. Immunology 2004; 113(2): 163-174.

32. Brinton CC Jr., Carter MJ, Derber DB, Kar S, Kramarik 
JA, Wood SW. Design and development of pilus vaccines for Haemophilus influenzae diseases. The pediatric infectious disease journal 1989; 8(Suppl. 1): S54- S61

33. Deich RA, Anilionis A, Fulginiti J, Metcalf BJ, Quataert S, Quinn-Dey T, Zlotnick SW, Green BA. Antigenic conservation of the 15,000-dalton outer membrane lipoprotein PCP of Haemophilus influenzae and biologic activity of anti-PCP antisera. Infection and immunity 1990; 58(10): 3388-3393.

34. Green BA, Farley JE, Quinn-Dey T, Deich RA, Zlotnick $\mathrm{GW}$. The e (P4) outer membrane protein of Haemophilus influenzae: biologic activity of anti-e serum and cloning and sequencing of the structural gene. Infection and immunity 1991; 59(9): 3191-3198.

35. Green BA, Quinn-Dey T, Zlotnick GW. Zlotnick. Biologic activities of antibody to a peptidoglycanassociated lipoprotein of Haemophilus influenzae against multiple clinical isolates of $H$. influenzae type $b$. Infection and immunity 1987; 55(12): 2878-2883.

36. Loeb MR. Protection of infant rats from Haemophilus influenzae type $\mathrm{b}$ infection by antiserum to purified outer membrane protein a. Infection and immunity 1987; 55(11): 2612-2618.

37. Munson RS Jr., Granoff DM. Purification and partial char-acterization of outer membrane proteins P5 and P6 from Haemophilus influenzae type $\mathrm{b}$. Infection and immunity 1985; 49(3): 544-549.

38. Munson RS, Jr, Sasaki K. Protein D, a putative immunoglobulin D-binding protein produced by Haemophilus influenzae, is glycerophos-phodiester phosphodiesterase. The journal of bacteriology 1993;175(14): 4569-4571.

39. Munson RS Jr., Shenep JL, Barenkamp SJ, Granoff DM. Purification and comparison of outer membrane protein P2 from Haemophilus influenzae type b isolates. The journal of clinical investigation 1983; 72(2): 677684.

40. Latz E, Franko J, Golenbock DT, Schreiber JR. Haemophilus influenzae type b-outer membrane protein complex glycoconjugate vaccine induces cytokine production by engaging human toll-like receptor 2 (TLR2) and requires the presence of TLR2 for optimal immunogenicity. The journal of immunology 2004; 172(4): 2431-2438.

41. Loeb MR, Smith DH. Outer membrane protein composition in disease isolates of Haemophilus influenzae: pathogenic and epidemiological implications. Infection and immunity 1980; 30(3): 709717.

42. Poolman JT, Bakaletz L, Cripps A, Denoel PA, Forsgren A, Kyd J, Lobet Y. Developing a nontypeable Haemophilus influenzae (NTHi) vaccine. Vaccine 2000; 19(Suppl 1): S108-S115.

43. Munson R Jr, Hunt A. Isolation and characterization of a mutant of Haemophilus influenzae type $\mathrm{b}$ deficient in outer membrane protein $\mathrm{P} 1$. Infection and immunity 1989; 57(3): 1002-1004.

44. Duim B, van Alphen L, Eijk P, Jansen HM, Dankert J. Antigenic drift of non-encapsulated Haemophilus influenzae major outer membrane protein $\mathrm{P} 2$ in patients with chronic bronchitis is caused by point mutations. Molecular microbiology 1994; 11(6): 1181-1189.

45. Kyd JM, Novotny LA, Bakaletz LO. Efficacy of the 26kilodalton outer membrane protein and two p5fimbrinderived immunogens to induce clearance of nontypeable HAemophilus influenzae from the rat middle ear and lungs aswell as from the chinchilla middle ear and nasopharynx. Infection and immunity 2003; 71(8): 46914699.

46. Reidl J, Mekalanos JJ. Lipoprotein e(P4) is essential for hemin uptake by Haemophilus influenzae. The Journal of experimental medicine 1996; 183(2): 621-629.

47. Reilly TJ, Chance DL, Smith AL. Outer membrane lipoprotein e (P4) of Haemophilus influenzae is a novel phosphomonoesterase. Journal of bacteriology 1999; 181(21): 6797-6805.

48. Badr WH, Loghmanee D, Karalus RJ, Murphy TF, Thanavala Y. Immunization of mice with P6 of nontypeable Haemophilus influenzae:kinetics of the antibody response and IgG subclasses. Vaccine 1999; 18(1-2): 29-37.

49. Berenson CS, Murphy TF, Wrona CT, Sethi S. Outer membrane protein p6 of nontypeable Haemophilus influenzae is a potent and selective inducer of human macrophage proinflammatory cytokines. 2005; 73(5): 2728-2735

50. $\mathrm{Hu} \mathrm{H}, \mathrm{He} \mathrm{L}, \mathrm{Hu}$ Y, Jiang M, Yao K, Yang Y. Detection of Haemophilus influenza type b DNA in a murine pneumonia model by in situ PCR. Journal of medical microbiology 2008; 57(Pt 10): 1282-1287.

51. Mandell GL BJ, Dollin R. Principles and practice of infectious disease. Churchill Livingstone: London; 2010.

52. Holland J, Parsons TR, Hasan AA, Cook SM, Stevenson P, Griffiths E, Williams P. Conservation and antigenic cross-reactivity of the transferrin-binding proteins of Haemophilus influenzae, Actinobacillus pleuropneumoniae and Neisseria meningitidis. Microbiology 1996; 142( Pt 12): 3505-3513.

53. Lima KM, dos Santos SA, Rodrigues JM Jr., Silva CL. Vaccine adjuvant: it makes the difference. Vaccine 2004; 19 (22-23): 2374-2379.

54. Ratledge C, Dover LG. Iron metabolism in pathogenic bacteria. Annual reviews microbiology 2000; 54:881941.

55. St Geme III JW FS. Haemophilus influenzae adheres to and enters cultured human epithelial cells. . Infection and immunity 1990; 58(12): 4036-4044.

56. Forsgren A, Grubb AO. Many bacterial species bind human IgD. The journal of immunological 1979; 122(4): 1468-1472.

57. Behrouzi A, Bouzari S, Siadat SD, Oloomi M, Davari M, Mazaheri H. Evaluation of the immunogenic property of NT H. influenzae protein D with Neisseria meningitidis OMV in BALB/c. The journal of infection in developing countries 2016; 10(12): 1345-1351.

58. $\mathrm{Wu} \mathrm{H}$, Tokunaga $\mathrm{M}$. Biogenesis of lipoproteins in bacteria. Current topics in microbiology and immunology 1986; 125: 127-157. 
59. Weinberg GA, Towler DA, Munson RS Jr., Lipoproteins of Haemophilus infiuenzae type b. Journal of Bacteriology 1988; 170(9): 4161- 4164.

60. Fan X, Goldfine H, Lysenko E, Weiser JN. The transfer of choline from the host to the bacterial cell surface requires glpQ in Haemophilus influenzae. Molecular microbiology 2001; 41(5): 1029-1103.

61. Shahini Shams Abadi M, Siadat SD, Vaziri F, Davari M, Fateh A, Pourazar S, Abdolrahimi F, and Ghazanfari M. Distribution and diversity of $h m w l A$ among invasive nontypeable Haemophilus influenzae isolates in iran. Avicenna journal of medical biotechnology 2016; 8(2): 99102.

62. Swords WE, Buscher BA, Ver SteegIi K, Preston A, Nichols WA, Weiser JN, Gibson BW, Apicella MA. Non-typeable Haemophilus influenzae adhere to and invade human bronchial epithelial cells via an interaction of lipooligosaccharide with the PAF receptor. Molecular microbiology 2000; 37(1): 13-27.

63. Swords WE, Ketterer MR, Shao J, Campbell CA, Weiser JN, Apicella MA. Binding of the non-typeable Haemophilus influenzae lipooligosaccharide to the PAF receptor initiates host cell signalling. Cellular microbiology 2001; 3(8): 525-536.

64. Craig JE, Cliffe A, Garnett K, High NJ. Survival of nontypeable Hae- mophilus influenzae in macrophages. FEMS microbiology letters 2001; 203(1): 55-61.

65. Arsang A, Tabatabaie A, Vaziri F, Nejati M, Zolfaghari MR, Fateh A, Rahimi Jamnani F, Bahrmand AR, Siadat SD. Optimization of large scale production of Haemophilus influenzae type $\mathrm{b}$ polyribosyl-ribitol phosphate. Minerva biotecnologica 2017; 29(1): 17-23.

66. Song XM, Forsgren A, Janson H. Glycerol-3-phosphate transport in Haemophilus influenzae: cloning, sequencing and transcriptional analysis of the glpT gene. Gene 1998; 215(2): 381-388.

67. Janson H, Hedén LO, Grubb A, Ruan M, Forsgren A. Protein D, an im-munoglobulin D-binding protein of Haemophilus influenzae: cloning, nucleotide sequence, and expression in Escherichia coli. Infection and immunity 1991; 59(1): 119-125.

68. Fleischmann RD, Adams MD, White O, Clayton RA, Kirkness EF, Kerlavage AR, Bult CJ, Tomb JF, Dougherty BA, Merrick JM, McKenney K, Sutton G, FitzHugh W, Fields C, Gocayne JD, Scott J, Shirley R, Liu L, Glodek A, Kelley JM, Weidman JF, Phillipps CA, Spriggs T, Hedblom E, Cotton MD, Utterback TR, Hanna MC, Nguyen DT, Saudek DM, Brandon RC,
Fine, LD, Fritchman JL, Fuhrmann JL, Geoghagen NSM, Gnehm CL, McDonald LA, Small KV, Fraser CM, Smith HO, Venter JC. Whole-genome random sequencing and assembly of Haemophilus influenzae Rd. Science 1995; 269(5223): 496-512.

69. Wilson R, Read R, Cole P. Interaction of Haemophilus influenzae with mucus, cilia, and respiratory epithelium. The journal of infectious diseases 1992; 165(Suppl 1): S100-S102.

70. Bluestone CD. Clinical course, complications and sequelae of acute otitis media. The pediatric infectious disease journal 2000; 19(5 Suppl): S37- S46.

71. Behrouzi A, Bouzari S, Siadat SD, Jafari A, Irani S. Molecular Cloning, Expression and Purification of Truncated hpd Fragment of Haemophilus influenzae in Escherichia coli. Jundishapur journal of microbiology 2015; 8(8): e23218.

72. Davoudi Vijeh Motlagh A, Siadat SD, Abedian Kenari S, Mahdavi M, Behrouzi A, Asgarian-Omran $\mathrm{H}$. Immunization with Protein D from Non-Typeable Haemophilus influenzae (NTHi) induced cytokine responses and bioactive antibody production. Jundishapur journal of microbiology 2016; 9(10): e36617.

73. Murphy TF. Current and future prospects for a vaccine for nontypeable Haemophilus influenzae. Current infectious disease reports 2009; 11(3): 177-182.

74. Winter LE, Barenkamp SJ. Antibodies to the HMW1/HMW2 and Hia adhesins of nontypeable Haemophilus influenzae mediate broad-based opsonophagocytic killing of homologous and heterologous strains. Clinical and vaccine immunology 2014; 21: 613-621.

75. Fink DL, Buscher AZ, Green B, Fernsten P, St Geme JW 3rd. The Haemophilus influenzae Hap autotransporter mediates microcolony formation and adherence to epithelial cells and extracellular matrix via binding regions in the $\mathrm{C}$-terminal end of the passenger domain. Cellular microbiology 2003; 5(3): 175-186.

76. Tabatabaee Bafroee A, Siadat SD, Mousavi SF, Aghasadeghi MR, Khorsand H, Nejati M, Sadat SM, Mahdavi M. Recombinant C-terminal 311 amino acids of HapS adhesin as a vaccine candidate for nontypeable Haemophilus influenzae: A study on immunoreactivity in Balb/C mouse. Microbial pathogenesis 2016; 98:106111. 